\title{
Front Matter: Volume 9284
}

, "Front Matter: Volume 9284," Proc. SPIE 9284, 7th International Symposium on Advanced Optical Manufacturing and Testing Technologies:

Optoelectronics Materials and Devices for Sensing and Imaging, 928401 (2 September 2014); doi: 10.1117/12.2083799

SPE Event: 7th International Symposium on Advanced Optical Manufacturing and Testing Technologies (AOMATT 2014), 2014, Harbin, China 


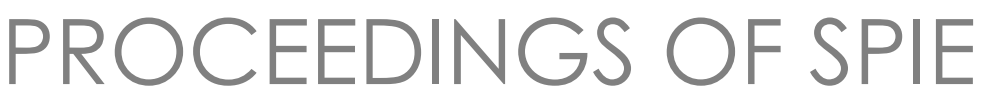

\section{7th International Symposium on Advanced Optical Manufacturing and Testing Technologies}

\section{Optoelectronics Materials and Devices for Sensing and Imaging}

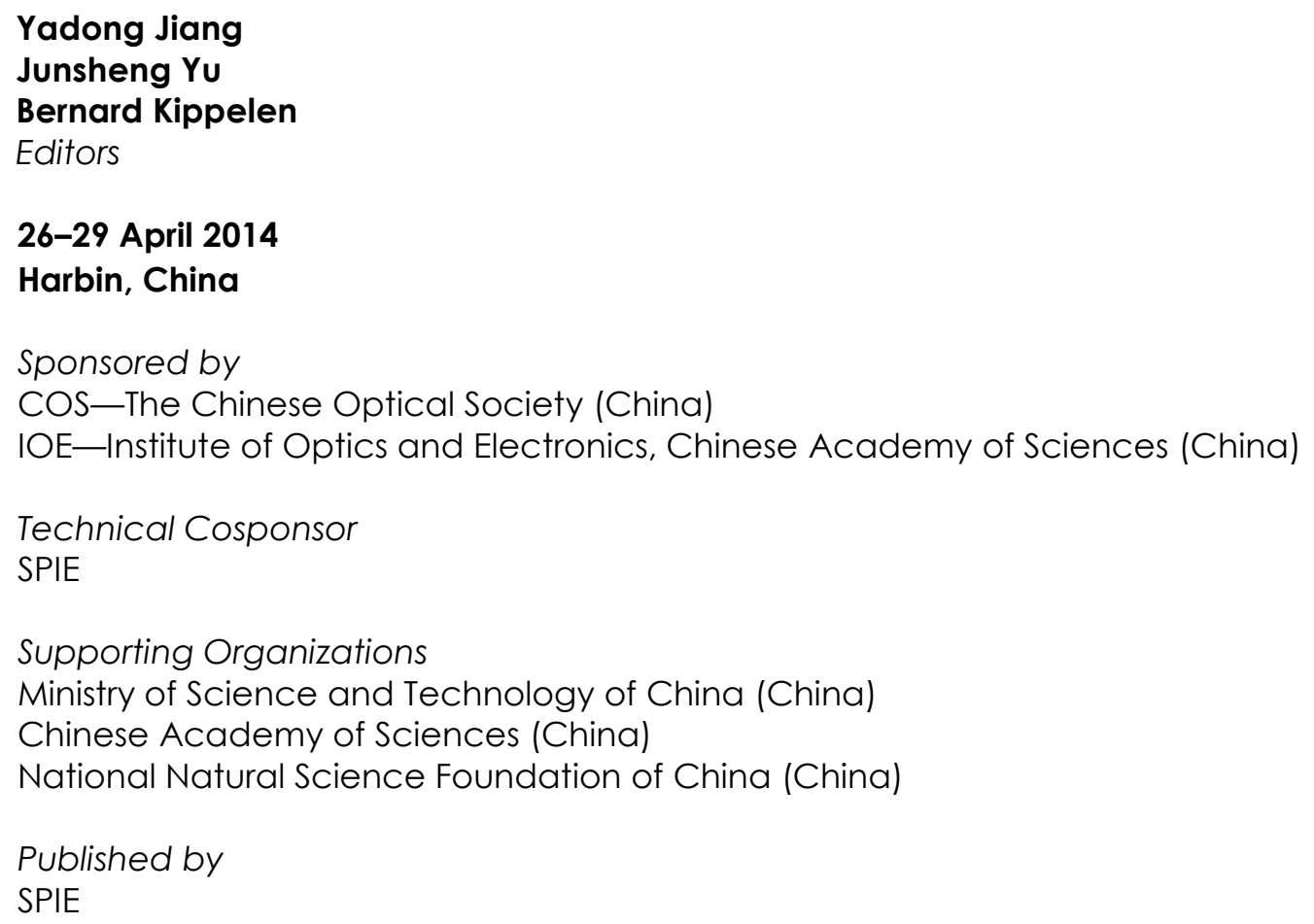


The papers included in this volume were part of the technical conference cited on the cover and title page. Papers were selected and subject to review by the editors and conference program committee. Some conference presentations may not be available for publication. The papers published in these proceedings reflect the work and thoughts of the authors and are published herein as submitted. The publisher is not responsible for the validity of the information or for any outcomes resulting from reliance thereon.

Please use the following format to cite material from this book:

Author(s), "Title of Paper," in 7th International Symposium on Advanced Optical Manufacturing and Testing Technologies: Optoelectronics Materials and Devices for Sensing and Imaging, edited by Yadong Jiang, Junsheng Yu, Bernard Kippelen, Proceedings of SPIE Vol. 9284 (SPIE, Bellingham, WA, 2014) Article CID Number.

ISSN: 0277-786X

ISBN: 9781628413595

Published by

SPIE

P.O. Box 10, Bellingham, Washington 98227-0010 USA

Telephone +1 3606763290 (Pacific Time) · Fax +1 3606471445

SPIE.org

Copyright (C) 2014, Society of Photo-Optical Instrumentation Engineers.

Copying of material in this book for internal or personal use, or for the internal or personal use of specific clients, beyond the fair use provisions granted by the U.S. Copyright Law is authorized by SPIE subject to payment of copying fees. The Transactional Reporting Service base fee for this volume is $\$ 18.00$ per article (or portion thereof), which should be paid directly to the Copyright Clearance Center (CCC), 222 Rosewood Drive, Danvers, MA 01923. Payment may also be made electronically through CCC Online at copyright.com. Other copying for republication, resale, advertising or promotion, or any form of systematic or multiple reproduction of any material in this book is prohibited except with permission in writing from the publisher. The CCC fee code is 0277-786X/14/\$18.00.

Printed in the United States of America.

Publication of record for individual papers is online in the SPIE Digital Library.

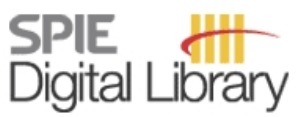

SPIEDigitallibrary.org

Paper Numbering: Proceedings of SPIE follow an e-First publication model, with papers published first online and then in print and on CD-ROM. Papers are published as they are submitted and meet publication criteria. A unique, consistent, permanent citation identifier (CID) number is assigned to each article at the time of the first publication. Utilization of CIDs allows articles to be fully citable as soon as they are published online, and connects the same identifier to all online, print, and electronic versions of the publication. SPIE uses a six-digit CID article numbering system in which:

- The first four digits correspond to the SPIE volume number.

- The last two digits indicate publication order within the volume using a Base 36 numbering

system employing both numerals and letters. These two-number sets start with 00, 01, 02, 03, 04, $05,06,07,08,09,0 A, 0 B \ldots 0 Z$, followed by 10-1Z, 20-2Z, etc.

The CID Number appears on each page of the manuscript. The complete citation is used on the first page, and an abbreviated version on subsequent pages. Numbers in the index correspond to the last two digits of the six-digit CID Number. 


\section{Contents}

ix Symposium Committee

xi Introduction

xiii AOMATT 2014 Sponsors

\section{ORAL SESSION}

928402 Development of the large area MCP-PMT [9284-54]

S. Liu, Y. Wang, T. Zhao, Institute of High Energy Physics (China); H. Liu, Xi'an Institute of Optics and Precision Mechanics (China); S. Si, North Night Vision Technology Group Co., Ltd. (China); J. Tian, Xi'an Institute of Optics and Precision Mechanics (China); S. Qian, Institute of High Energy Physics (China); J.-N. Sun, North Night Vision Technology Group Co., Ltd. (China); X. Cai, Institute of High Energy Physics (China); D. Li, L. Chen, Xi'an Institute of Optics and Precision Mechanics (China); B. Yan, Y. Yang, Institute of High Energy Physics (China)

928403 Research on polarizing performance of $\mathrm{Au}-\mathrm{SiO}_{2}$ sub-wavelength hybrid grating in short wave infrared (SWIR) [9284-48]

W. Rui, Shanghai Institute of Technical Physics (China) and Univ. of Chinese Academy of Sciences (China); T. Li, X. Shao, X. Li, H. Gong, Shanghai Institute of Technical Physics (China)

928404 Highly efficient non-doped orange-red phosphorescent organic light-emitting devices based on a novel iridium complex [9284-53]

Y. Qi, X. Wang, Univ. of Electronic Science and Technology of China (China); M. Li, Sichuan Univ. (China); J. Yu, Univ. of Electronic Science and Technology of China (China); Z. LU, Sichuan Univ. (China)

928405 High photo-response organic ultraviolet photodectectors based on phosphorescent materials [9284-25]

X. Wang, J. Yu, J. Huang, Univ. of Electronic Science and Technology of China (China)

928406 Performance of extended wavelength InGaAs/InAsP SWIR detector [9284-47]

G. Cao, Shanghai Institute of Technical Physics (China) and Univ. of Chinese Academy of Sciences (China); T. Li, H. Tang, X. Shao, X. Li, H. Gong, Shanghai Institute of Technical Physics (China)

928407 Characteristic analysis on the thermal noise of infrared CCD [9284-58]

R.-Z. Zhang, X. Yu, Sichuan Univ. (China); G.-D. Liu, Institute of Fluid Physics (China)

928408 The transmission characteristics of laser in multilayer coatings [9284-18]

L. Du, R. Zhang, Sichuan Univ. (China) 
928409 Smell sensing and visualizing based on multi-quantum wells spatial light modulator [9284-10]

F. Tian, Z. Zhao, P. Jia, H. Liao, D. Chen, Chongqing Univ. (China); S. Liu, Chongqing Academy of Metrology and Quality Inspection (China)

\section{POSTER SESSION}

9284 OA Influence of bandgap grading of intrinsic layer and annealing post on the optical and electrical performance of amorphous silicon germanium thin film solar cells [9284-1] B. Yan, S. Liu, Institute of High Energy Physics (China); L. Zhao, W. Wang, Institute of Electrical Engineering (China); Y. Yang, Guangxi Univ. (China)

9284 OB BBO crystal component design for ultra-short laser pulse measurement [9284-65] Y. Jia, X. Zhang, Beijing Information Science and Technology Univ. (China); T. Zhang, Air Defense Forces Academy (China); L. Lu, Beijing Information Science and Technology Univ. (China)

9284 OC The effect of spin coating parameters on the performance of PTB7/PC 71 BM polymer solar cells [9284-46]

J. Li, S. Li, Y. Zheng, J. YU, Univ. of Electronic Science and Technology of China (China)

9284 OD Star point centroid algorithm based on background forecast [9284-28]

J. Wang, Institute of Optics and Electronics (China) and Univ. Of Electronic Science and Technology of China (China); R. Zhao, Institute of Optics and Electronics (China); N. Zhu, Beijing Institute of Control Engineering (China)

9284 OE Study of an image restoration method based on Poisson-maximum likelihood estimation method for earthquake ruin scene [9284-13]

Y. Song, J. Yang, L. Cheng, S. Liu, Institute of Disaster Prevention (China)

9284 OF Detailed analysis of bulk heterojunction organic solar cells based on P3HT:PCBM [9284-12] J. Zhong, M. Deng, F. Gan, H. Chen, L. Wang, Univ. of Electronic Science and Technology of China (China)

9284 OG A method of color correction of camera based on HSV model [9284-62] R. Zhao, J. Wang, G. YU, J. Zhong, W. Zhou, Institute of Optics And Electronics (China); Y. Li, Shanghai Aerospace Control Technology Research Institute (China)

$9284 \mathrm{OH} \quad$ Study on photoemission surface of varied doping GaN photocathode [9284-61] J. Qiao, R. Du, Nanyang Institute of Technology (China); H. Ding, Nanjing Univ. of Science and Technology (China); Y. Gao, Nanyang Institute of Technology (China); B. Chang, Nanjing Univ. of Science and Technology (China)

9284 Ol Star identification independence on the camera parameters [9284-60]

D. Su, Naval Aeronautical and Astronautical Univ. (China); D. Chen, New Star Research Institute of Applied Technology (China); M. Zhou, K. Wang, Naval Aeronautical and Astronautical Univ. (China)

$92840 \mathrm{~J}$ Comparison of dye doping and ultrathin emissive layer in white organic light-emitting devices with dual emissive layers [9284-16]

X. Wang, Y. Qi, J. Yu, Univ. Of Electronic Science and Technology of China (China) 
9284 OK Measurement error analysis of three dimensional coordinates of tomatoes acquired using the binocular stereo vision [9284-34]

R. Xiang, China Jiliang Univ. (China)

$9284 \mathrm{OL} \quad$ Some improvements on the auto-gated power for low-light level image intensifier [9284-35] Y. Yang, B. Yan, Q. Zhi, Z. Yao, J. Li, L. Fu, Y. Yuan, G. Deng, Science and Technology on Low-Light-Level Night Vision Lab. (China) and North Night Vision Technology Group Co., Ltd. (China)

9284 OM The study of the effect on the organic emitting diodes with (t-bt) 2 Ir(acac) as deep hole-trap [9284-72]

M. Deng, J. Zhong, K. Gu, J. Chen, Y. Chen, Univ. of Electronic Science and Technology of China (China)

9284 ON A multi-focus image adaptive fusion method based on comprehensive index [9284-27] H. LU, Xi' an Institute of Optics and Precision Mechanics (China) and Univ. of Chinese Academy of Sciences (China); Z. Song, W. Gao, Xi'an Institute of Optics and Precision Mechanics (China); Q. Wang, J. Xi, Xi'an Institute of Optics and Precision Mechanics (China) and Univ. of Chinese Academy of Sciences (China)

928400 Compressed sensing based on the improved wavelet transform for image processing [9284-32]

P. Pang, Xi' an Institute of Optics and Precision Mechanics (China) and Univ. Of Chinese Academy of Sciences (China); W. Gao, Z. Song, Xi' an Institute of Optics and Precision Mechanics (China); J. XI, Xi' an Institute of Optics and Precision Mechanics (China) and Univ. of Chinese Academy of Sciences (China)

9284 OP Properties of InGaN P-I-N ultraviolet detector [9284-70]

Y. LU, Shanghai Institute of Technical Physics (China) and Univ. of Chinese Academy of Sciences (China); Y. Zhang, X. Li, Shanghai Institute of Technical Physics (China)

$9284 \mathrm{OQ} \quad$ Maneuvering target tracking based on multiple model methods [9284-71]

S. Li, Univ. of Chinese Academy of Sciences (China) and Institute of Optics and Electronics (China) and Key Lab. of Beam Control (China); Q. Bao, Institute of Optics and Electronics (China) and Key Lab. of Beam Control (China)

9284 OR An analysis of the optimal size of image sensors in free space optic systems [9284-8] L. Li, Institute of Optics and Electronics (China) and Univ. of Chinese Academy of Sciences (China); Y. Huang, T. An, Institute of Optics and Electronics (China)

9284 OS Infrared absorption mechanisms of black silicon [9284-36]

Z. Cheng, Y. Chen, B. Ma, Shanghai Institute of Technical Physics (China)

9284 OT Change of the surface potential barrier of GaAs photocathode during two-step activation [9284-66]

J. Niu, Nanjing Univ. of Science and Technology (China) and Nanyang Institute of Technology (China); Y. Gao, Y. Qian, B. Chang, Nanjing Univ. of Science and Technology (China) 
$9284 \mathrm{OU}$ Effects of thermal annealing on photoluminescence spectra in $\pi$-conjugated polymer film: evidence for dual emission by temperature dependent measurements [9284-4] R. Z. Wang, X. Yang, Y. C. Wang, C.-X. Sheng, Q. Chen, Nanjing Univ. of Science and Technology (China)

9284 OV Continuous-wave photoinduced absorption studies in long lived photoexcitation of $\pi$-conjugated polymer and fullerene blended films [9284-6]

X. Yang, H. Li, Y. C. Wang, R. Z. Wang, C.-X. Sheng, Nanjing Univ. of Science and Technology (China)

9284 OW Measurements of amplified spontaneous emission in $\pi$-conjugated polymer films with different morphology [9284-7]

Y. Wang, X. Yang, R. Wang, C. Sheng, Nanjing Univ. of Science and Technology (China)

9284 0X A hole-filling algorithm based on pixel labeling for DIBR [9284-45]

L. Lei, Z. Chen, J. Shi, Yunnan Normal Univ. (China)

9284 OY Influence of ageing processing on GaAs photocathode of $3^{\text {rd }}$ generation low-light-level image intensifier [9284-38]

L. Feng, F. Shi, L. Yin, Z. Miao, H. Cheng, L. Wang, S. Niu, X. Zhang, Science and Technology on Low-Light-Level Night Vision Lab. (China) and North Night Vision Technology Group Co., Ltd. (China)

$92840 Z$ Arsenic volatilization of GaAs photocathode at low temperature during thermal cleaning [9284-42]

H. Liu, F. Shi, Z. Miao, X. Gao, H. Cheng, S. Niu, L. Wang, C. Chen, Science and Technology on Low-Light-Level Night Vision Lab. (China) and North Night Vision Technology Group Co., Ltd. (China)

928410 Characteristic of photocurrent decline of transmission-mode equally doped GaAs photocathode [9284-43]

D. Zhang, F. Shi, X. Gao, H. Cheng, Z. Miao, S. Niu, L. Wang, C. Chen, Science and Technology on Low-Light-Level Night Vision Lab. (China) and North Night Vision Technology Group Co., Ltd. (China)

928411 Analysis of electric vacuum characteristics of MCP [9284-39]

X. Gao, F. Shi, H. Cheng, L. Yin, Z. Miao, X. Cheng, L. Wang, S. Niu, Science and Technology on Low-Light-Level Night Vision Lab. (China) and North Night Vision Technology Group Co., Ltd. (China)

928412 An improved method of edge detection based on the mean shift algorithm [9284-33] L. Wei, B. Liu, J. Mou, Xi'an Institute of Optics and Precision Mechanics (China)

928413 The simulation and analysis of infrared target multi-band characteristics [9284-31] L. Cui, Institute of Optics and Electronics (China) and Univ. of the Chinese Academy of Sciences (China); J. Zhou, Institute of Optics and Electronics (China) 
928414 Effects of pulse frequency on the microstructure, composition and optical properties of pulsed dc reactively sputtered vanadium oxide thin films [9284-11]

X. Dong, Z. WU, Y. Jiang, X. XU, H. YU, D. GU, T. Wang, Univ. of Electronic Science and Technology of China (China)

928415 Optoelectronic correlator based on YUV color model with shiffed training images for color image recognition [9284-40]

Y. Li, C. Chen, H. Chen, Y. Hsieh, Yuan Ze Univ. (Taiwan)

928416 Design of area array CCD image acquisition and display system based on FPGA [9284-41]

L. Li, N. Zhang, T. Li, Y. Pan, Y. Dai, Changchun Univ. of Science and Technology (China)

928417 Research of ion feedback-induced noise of micro-channel plate [9284-44]

D. Li, Y. Zhu, N. Zhang, J. Nie, F. Zhang, T. Zhang, S. Li, X. Liu, Z. Liu, Science and Technology on Low-Light-Level Night Vision Lab. (China) and North Night Vision Technology Group Co., Ltd. (China)

928418 Ghost detection and removal based on super-pixel grouping in exposure fusion [9284-63] S. Jiang, Z. XU, Q. Li, Y. Chen, H. Feng, Zhejiang Univ. (China)

928419 Blind deconvolution using an improved L0 sparse representation [9284-68]

P. Ye, H. Feng, Q. Li, Z. Xu, Y. Chen, Zhejiang Univ. (China)

$92841 \mathrm{~A}$ A study of the non-uniform current density influence in reactive sputtering deposition [9284-30]

T. Wang, H. Yu, C. Chen, Y. Wang, Y. Jiang, Univ. of Electronic Science and Technology of China (China)

$92841 \mathrm{C}$ Preparation and mechanical properties of the $\mathrm{MgAl}_{2} \mathrm{O}_{4}$ transparent phosphor ceramics [9284-17]

X. Bai, Z. Li, M. Lei, Z. Pang, Bright Crystals Technology Inc. (China)

9284 ID A low-temperature bridge-input CMOS circuit for low-impedance detector [9284-23]

H. Yuan, Y. Chen, Shanghai Institute of Technical Physics (China)

9284 IE Simulation of terahertz metamaterial absorbers with microbolometer structure [9284-20] J. Ding, J. Wang, X. Guo, Y. Jiang, L. Fan, Univ. of Electronic Science and Technology of China (China)

9284 IF Study on preparation and polarization process of PVDF thin film [9284-15]

X. Guo, J. Wang, J. Ding, Y. Jiang, Univ. of Electronic Science and Technology of China (China) 
9284 IG Cooperative chemisorption of $K$ and $O$ elements on cleaved GaAs(110) surface [9284-51] B. Ren, Science and Technology on Low-Light-Level Night Vision Lab. (China) and North Night Vision Technology Group Co., Ltd. (China) and Beijing Institute of Technology (China); Z. Miao, Z. Hou, H. Cheng, F. Shi, G. Jiao, X. Bai, S. Niu, L. Wang, L. Fu, Science and Technology on Low-Light-Level Night Vision Lab. (China) and North Night Vision Technology Group Co., Ltd. (China)

$9284 \mathrm{1H} \quad$ Research on theory of the silicon material electro-optic modulator [9284-49]

Y. Zhang, W. Li, H. Liu, Jilin Jianzhu Univ. (China)

$928411 \quad$ An effective segmentation cue for moving object segmentation from a moving camera [9284-19]

S. Wang, Luoyang Institute of Electro-Optical Equipment (China); M. Wu, Luoyang Optoelectronic Technology Development Ctr. (China); Y. Xie, Luoyang Institute of ElectroOptical Equipment (China) and Science and Technology on Electro-optic Control Lab. (China)

Author Index 


\title{
Symposium Committee
}

\author{
Honorary Chair
}

Bingkun Zhou, Chinese Optical Society (China)

Symposium General Chair

Liwei Zhou, Beijing Optical Society (China)

Symposium General Co-chairs

Jianlin Cao, Ministry of Science and Technology of China

H. Philip Stahl, NASA Marshall Space Flight Center (United States)

Yudong Zhang, Institute of Optics and Electronics (China)

Larry Stepp, Thirty Meter Telescope Project (United States)

Yingchun Liang, Harbin Institute of Technology (China)

Yu Yao, Harbin Engineering University (China)

International Academic Committee

Wenhan Jiang, Chair, Chinese Academy of Engineering (China)

Liwei Zhou, Chinese Academy of Engineering (China) and Beijing Institute of Technology (China)

Harald Giessen, University of Stuttgart (Germany)

Junhua Pan, Chinese Academy of Engineering (China) and Soochow University (China)

Myung K. Cho, National Optical Astronomy Observatory (United States)

Organizing Committee

Yudong Zhang, Co-chair, IOE, CAS (China)

Jinghua Cao, Co-chair, Bureau of International Cooperation, CAS (China)

Libin Xiang, Co-chair, Shanghai Engineering Center for Microsatellites (China)

Yadong Jiang, Co-chair, University of Electronic Science and Technology (China) 
Program Committee

Xiangdi Lin, Chair, Chinese Academy of Engineering (China)

Hu Yang, Co-chair, IOE, CAS (China)

Wei Gao, Co-chair, Tohoku University (Japan)

Huadong Yu, Co-chair, Changchun University of Science and Technology (China)

Secretary General of the Symposium

Li Yang, Committee of Optical Manufacturing Technology, COS (China)

\title{
Session Chairs
}

\author{
Session 1-1 Fan Wu \\ Session 2-1 Qiming Xin \\ Session 3-1 Shangming Wen \\ Session 4-1 Tingwen Xin \\ Session 5-1 Xiao Wang \\ Session 6-1 Xiangang Luo \\ Session 1-2 Bin Fan \\ Session 2-2 Shengyi Li \\ Session 3-2 Rongzhu Zhang \\ Session 4-2 Qingliang Zhao \\ Session 5-2 Yige Qi \\ Session 6-2 Changtao Wang
}




\section{Introduction}

The 7th International Symposium on Advanced Optical Manufacturing and Testing Technology (AOMATT) was held 26-29 April 2014 at the Harbin International Conference Center, China.

AOMATT 2014 was kicked off with a formal opening ceremony. The ceremony started with the introduction of VIP guests, symposium chairs, conference chairs, and plenary speakers, followed by opening speeches by Prof. Liwei Zhou, AOMATT 2014 Symposium Chairman, Prof. Bin XU, Vice President of IOE, a sponsor of AOMATT 2014, and Prof. Yingchun Liang, Assistant President of Harbin Institute of Technology, a local co-sponsor of AOMATT 2014. Dr. H. Philip Stahl, 2014 President of SPIE, technical cosponsor of AOMATT 2014, could not attend the symposium this year due to a schedule conflict, but sent his congratulation letter. In his letter, Dr. Stahl gave high marks for AOMATT and stated:

AOMATT is a very successful collaboration between SPIE, the Institute of Optics and Electronics of the Chinese Academy of Sciences, and the Chinese Optical Society. It has become a well-known international symposium on advanced optical manufacturing and testing technologies. The vision of AOMATT is closely aligned with SPIE's mission to promote optics and photonics around the world.

All of the conference sponsors and attendees greatly appreciate SPIE and Dr. Stahl's long-standing support of AOMATT since its inception in 2002.

The plenary sessions started immediately after the conclusion of the opening ceremony. There were a total of nine plenary presentations: Dr. Larry Stepp, Telescope Department Head for the Thirty Meter Telescope (TMT) Project, USA, presented "Manufacturing the Optics for the Thirty Meter Telescope"; Dr. Bernard Delabre, Optical Design Engineer of European Southern Observatory (ESO), Germany, presented "The Progress of the European Extremely Large Telescope"; Dr. Tao Sun, Director of the Centre for Precision Engineering(CPE) of Harbin Institute of Technology, presented "Method and procedure for the highefficiency and ultra-precision diamond turning of large optical mirrors"; Dr. Wei Gao, Professor and Director of Research Center for Precision Nanosystems, Dept. of Nanomechanics of Tohoku University, Japan, presented "Precision nanometrology for fabrication of micro optics"; Dr. Xuejun Zhang, Vice President of Changchun Institute of Optics, Fine Mechanics and Physics (CIOMP), CAS, presented "Advanced manufacturing and testing technologies for multiple mirror space telescopes"; Dr. A.G. Poleshchuk, Head of the Laboratory of Diffractive Optics, and Dr. Victor P. Korolkov, senior scientist of Institute of Automation and Electrometry, Siberian Branch of Russian Academy of Sciences, Novosibirsk, Russia, presented "Diffractive optical elements: fabrication and application"; Dr. 
Axel Schindler, Science and Technology Consultant of Leibniz Institute of Surface Modification (IOM), Germany, presented "Advanced ion beam finishing and atmospheric plasma technology for high end optics"; Dr. Harald Giessen, Chair for Ultrafast Nano-Optics in the Department of Physics at the University of Stuttgart, Germany, presented "Complex hybrid plasmonics: new materials and new functionalities"; Dr. Xiangang Luo, Director of State Key Laboratory of Optical Technologies on Nano-Fabrication and Micro-Engineering of Institute of Optics and Electronics, CAS, presented "Manipulating the polarization states of electromagnetic waves using subwavelength structures". More than 600 people attended the opening ceremony and the full-day plenary sessions.

More than 400 oral and poster papers were selected for AOMATT 2014. About 102 oral papers were presented in six parallel conference sessions on 27 April. A special Technical Workshop was held in the morning of 28 April. An all-symposium poster session was held in the afternoon of 28 April. Authors and attendees had active discussions and exchange of ideas throughout the symposium. Many papers presented cutting-edge research and development work in optical design, manufacturing, and testing. The success of AOMATT 2014 continued the tradition of focus and excellence of this biannual international topical symposium in China.

We would like to express our sincere appreciation to COS-The Chinese Optical Society, IOE-Institute of Optics and Electronics, Chinese Academy of Sciences, and to SPIE for sponsoring and supporting AOMATT 2014. We would like to thank all chairs, committee members, authors, and attendee for their contributions to the symposium and sharing their research with colleagues around the world.

The 8th AOMATT is planned for 2016, and we look forward to seeing everyone at AOMATT 2016. Please watch for the Call for Papers and symposium announcements on the SPIE, IOE and COS web sites. 


\section{AOMATT 2014 SPONSORS}

Sponsored by

COS-The Chinese Optical Society

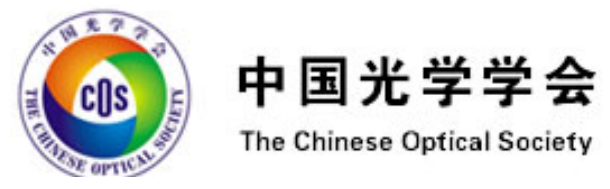

IOE-Institute of Optics and Electronics, Chinese Academy of Sciences

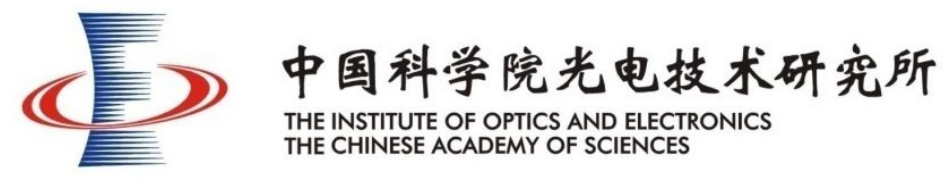

Technical Cosponsor

SPIE

\section{SPIE.}

Supporting Organizations

Ministry of Science and Technology of China

Chinese Academy of Sciences

National Natural Science Foundation of China

Cooperating Organizations

Harbin Institute of Technology (China) • Harbin Engineering University (China) • National University of Defense Technology (China) - University of Electronic Science and Technology of China - Sichuan University (China) - Sichuan Optical Society - State Key Laboratory of Optical Technologies on Nano-Fabrication and Micro-Engineering, IOE, CAS • Key Laboratory of Adaptive Optics, IOE, CAS • Changchun Institute of Optics, Fine Mechanics and Physics (China) - Beijing Institute of Technology (China) • Changchun University of Science and Technology (China) 
Proc. of SPIE Vol. $9284928401-14$

Downloaded From: https://www.spiedigitallibrary.org/conference-proceedings-of-spie on 26 Apr 2023 Terms of Use: https://www.spiedigitallibrary.org/terms-of-use 